\title{
Pheromone trap and crop infestation monitoring of mealybug species in Nelson apple orchards
}

\author{
P.W. Shaw and D.R. Wallis \\ The New Zealand Institute for Plant \& Food Research Limited, Old Mill Road, RD3, Motueka, \\ New Zealand \\ Corresponding author: peter.shaw@plantandfood.co.nz
}

Potential applications for synthetic sex pheromones for two troublesome mealybug species found in New Zealand, Pseudococcus calceolariae (citrophilus) and P. longispinus (longtailed), are ongoing. The aim of this pilot study was to compare the results of season-long pheromone trapping for both species with crop infestation assessments at harvest. A total of four traps of each species was monitored in three commercial Nelson orchard blocks between September 2010 and April 2011. Trapping indicated a sharp peak in male citrophilus mealybug flight activity in mid February with a gradual decline thereafter. Longtailed mealybug flight activity increased during March and peaked in late April when trapping ceased. Higher numbers of citrophilus mealybug males $(36,764)$ were trapped than longtailed mealybug (693). At harvest, mealybugs were identified on 357 infested fruit and 295 infested leaves to determine mealybug species composition and relative abundance. The dominant species was longtailed mealybug, identified on $92 \%$ of infested fruit. Citrophilus and obscure mealybugs ( $P$. viburni) were identified on 3 and 5\% of infested fruit respectively. From the leaf sample 410 longtailed, 4 obscure and no citrophilus mealybugs were identified. These results indicate pheromone trap catches do not reflect species abundance in the crop. Possible reasons for these results are discussed.

\section{Time and temperature combinations that are lethal to Pseudomonas syringae pv. actinidiae}

\author{
I.P.S. Pushparajah and K.R. Everett \\ The New Zealand Institute for Plant E Food Research Limited, Private Bag 92169, Mt Albert, \\ Auckland 1142, New Zealand \\ Corresponding author: Kerry.Everett@plantandfood.co.nz
}

The thermal death point was determined in vitro for three isolates of Pseudomonas syringae pv. actinidiae (Psa). A bacterial suspension was treated by placing in an Eppendorf tube then floating in a water bath at seven temperatures, from 26.3 to $60^{\circ} \mathrm{C}$. At each temperature an aliquot was removed after $5,15,35,75$, 155, 315 and 635 min, placed onto King's medium B (KMB) in Petri plates and spread with a sterilised bent glass rod. Petri plates were placed at $25^{\circ} \mathrm{C}$ for $24 \mathrm{~h}$ and colonies counted. There were three isolate replicates each in an Eppendorf tube per time:temperature combination. There was no difference in response between isolate replicates, but time and temperature differences were significant $(\mathrm{P}<0.0001)$. Any time:temperature combination greater than $45^{\circ} \mathrm{C}$ for 5 min killed Psa. Modelling the thermal response suggested that $42.5^{\circ} \mathrm{C}$ for longer than $150 \mathrm{~min}$ was the lowest time:temperature combination that could be used to kill the bacterial cells. 